\title{
Extended Release Floating Microballoons Containing Clerodendrum colebrookianum Extract: In vitro in vivo Evaluation
}

\author{
Daphisha Marbaniang ${ }^{1 *}$, Ratna Jyoti Das ${ }^{1}$, Paulami Pal ${ }^{1}$, Ananta Saikia ${ }^{2}$, Manash Pratim Pathak ${ }^{1,3}$, \\ Santa Manda| ${ }^{3,4}$, Nilutpal Sharma Bora ${ }^{1,3}$, Anup Kumar Das ${ }^{5}$, Pronobesh Chattopadhyay ${ }^{3}$, Subhabrata \\ Ray $^{6}$, Bhaskar Mazumder ${ }^{1}$
}

1'Department of Pharmaceutical Sciences, Dibrugarh University, Dibrugarh, Assam, INDIA.

${ }^{2}$ Pratiksha Institute of Pharmaceutical Sciences, Panikhaiti, Assam, INDIA.

${ }^{3}$ Division of Pharmaceutical Technology, Defence Research Laboratory, Tezpur, Assam, INDIA.

${ }^{4}$ School of Pharmaceutical Sciences, IFTM University, Moradabad, Uttar Pradesh, INDIA.

${ }^{5}$ Department of Pharmaceutical Technology, Adamas University, Barasat, West Bengal, INDIA.

${ }^{6}$ Dr. B.C.Roy College of Pharmacy and Allied Health Sciences, Bidhan Nagar, Durgapur, West Bengal, INDIA.

\begin{abstract}
Aims: Microballoons are floating particulate system comprising of a hollow core, drug being loaded within the polymeric layer. The aim of the study was to prepare microballoons containing extract of Clerodendrum colebrokianum, as bioactive agent. Methods: The microballoons were prepared by solvent diffusion technique, prepared microballoons were physico-chemically characterized (Scanning Electron Microscopy (SEM), buoyancy determination, entrapment efficiency, etc), in vitro drug release study and estimated for its in vivo antihypertensive activity by $2 \mathrm{~K} 1 \mathrm{C}$ hypertension induction method. Results: SEM confirmed the microballoons to be spherical with porous surfaces and hollow core. The developed formulation showed a buoyancy varying from $70.18 \%-89.90 \%$. The entrapment efficiency of bioactives in microballoons was found between $52 \%-69 \%$ with a delayed release of maximum $28 \%$ in $8 \mathrm{hr}$ as found from in vitro drug release study. In vivo antihypertensive studies carried out in rat model showed C. colebrookianum extract have good antihypertensive activity in both high and low dose with respect to standard propanolol. The formulations containing both doses were further found to be effectual in the treatment of hypertension because of its floating nature. Conclusion: The results suggested that optimized formulation show an effective extended release of Clerodendrum colebrokianum extract for the treatment of hypertension.
\end{abstract}

Key words: Microballoons, Antihypertensive agent, Encapsulation, Floating drug delivery system, 2K1C hypertension induction method.

\section{INTRODUCTION}

Cardiovascular diseases are known worldwide as primary cause of death. It includes Heart attacks, cerebrovascular disease, Hypertension, Periphery artery disease, heart failure, congenital heart disease and Rheumatic heart disease. ${ }^{1}$ Hypertension is identified as the continuous increased in pressure in the blood vessels. Hypertension can cause other disorders like rupture of blood vessels, kidney failure, blindness and cognitive impairment. ${ }^{2}$ Treatment of hypertension by consumption of diet containing antioxidant effect is said to be effective and less costly. Thus consumption of antioxidants which occurs naturally from the daily diet or taken as dietary supplements can help us to maintain a proper metabolic process that are essential for quenching of Reactive Oxygen Species (ROS). The Dietary Approaches to Stop Hypertension (DASH) studies have revealed that blood pressure can be lowered effectively by consuming diet enriched with all these rich nutrients. ${ }^{3}$ Thereby, use of
Submission Date: 21-12-2018; Revision Date: 29-03-2019; Accepted Date: 28-06-2019

DOI: 10.5530/ijper.53.3s.94 Correspondence: Ms. Daphisha Marbaniang, Department of Pharmaceutical Sciences, Dibrugarh University, Dibrugarh- 786004, Assam, INDIA.

Phone: +91-8011803483

E-mail: daphishamarbaniang@gmail.com

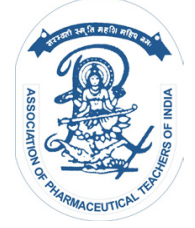

www.ijper.org 
natural sources containing antioxidant activity which are consumed as vegetables are said to be beneficial.

Clerodendrum colebrookianum Walp., belonging to Family Verbenaceae, a medicinal plant used widely by the people of northeast India as a cardio protective agent. It is prevalently known in English as "East Indian Glory Bower", "Phuinum" in Mizoram, as "Nefafu" in Assam, Khasi as "Jarem", in Manipur as "Kuthap" and "Phuihong" in Nagaland. ${ }^{4}$ Ethnic population of Mizoram claims that the plant is having a potent hypotensive action when consumed on a regular basis. Phytochemical investigation shown the existence of triacontane, amyrin, clerodin, (24s) ethyl cholesta 5, 22, 25 trien 3-ol, $\beta$-sitosterol, clerodendoside, daucosterol, clerosterol, colebrin A-E, clerodolone. ${ }^{5}$ The leaves and leaf twigs are used for treatment of higher blood pressure, abdominal pain, as an anthelmintic, blood purifier, in treatment of infant's cough and also for the treatment of diabetes by the north-eastern folks of India. The tender stem is used to treat any gastric disorders. People from Mizoram and Arunachal Pradesh used the extract from the roots part for the treatment of diarrhea and dysentery. ${ }^{6}$ Extraction of the plant and then formulated it in a dosage form (microballoons) can increase the efficacy against hypertension and also for ease administration.

Floating drug delivery systems (Microballoons) consist of a central hollow space where the API is loaded within the polymer layer which are developed in such a manner that they have less density than the gastric fluid and can float or continue to float in the stomach, thereby overcoming the drawbacks by increasing the Gastric Residence Time (GRT) or decreased GI transit of the dosage form. The floating mechanisms of such formulations involve swelling and expanding, mucoadhesion and effervescent systems. ${ }^{7,8}$

The current study was designed with the hypothesis that when C. colebrookianum extract was formulated as microballoons, the polymeric matrix will release the potent phytocompound in a sustained manner so as to maintain the effective therapeutic level in the body over an extended period of time and thus eliminating possibility of multiple administrations.

\section{MATERIALS AND METHODS}

\section{Materials}

Ethylcellulose, Hydroxypropyl methylcellulose [molecular weight: 59.08708 ; viscosity grade of $2 \%(\mathrm{w} / \mathrm{w})$ solution: 4-6 cps], Methylcellulose (viscosity: 3000-5000 mPa.s), Polyvinylpyrrolidone (PVP K-30), Polyvinyl alcohol (molecular weight: 140,000), Tween 80, Carboxy meth- ylcellulose high viscosity (CMC) and Hydrochloric acid were purchased from Himedia, Mumbai. Sodium Chloride was purchased from Qualigens. Aluminium Chloride and Folin-Ciocalteau reagent was purchased from Merck. All other reagents and solvents used were of analytical grade and used without further purification.

\section{Collection and authentication of plant material}

The leaves of Clerodendrum colebrookianum Walp. were collected from Sivsagar district of Assam, India during the month of June-July and January-February. The leaves were washed thoroughly followed by shade drying and were preserved as herbarium sheet. The authentication was carried out in Botanical Survey of India (BSI), Eastern Regional Centre, Shillong, authentication number being DU/PSC/HRB/DM/1/2016.

\section{Preparation of Plant Extract}

The shade dried leaves were grinded to obtain powder passing through sieve no 60 of ASTM series. About $500 \mathrm{~g}$ of the grounded leaves were taken and extracted using a Soxhlet apparatus at $40^{\circ} \mathrm{C}$ with ethanol as a solvent. The extraction was continue for $72 \mathrm{hr}$. The extract was transferred to a petridish and was concentrated to a dry mass with rotary evaporator (BUCHI, Switzerland) followed by lyophilization (IIC, India) at $-40^{\circ} \mathrm{C}$ into a dried mass by lyophilyzer.

\section{Phytochemical evaluation of plant extract}

Plants do not consist only of carbohydrates, proteins and lipids as chemical components but other secondary metabolites, which gives physiological and therapeutic effects. Therefore, the extracted material was subjected to various preliminary phytochemical screening for the detection of various secondary metabolites. Detection of alkaloid (Mayer's test, Wagner's test, Dragendorff's test, Hager's test) , carbohydrate (Fehling's test, Molish's test, Barfoed's test, Benedict's test), phenols (Gelatin Test, Ferric Chloride Test), saponins, glycosides (Lead Acetate Test, Borntrager's test), flavonoids (Magnesium and Hydrochloric acid reduction/Shinoda test, Alkaline reagent test), proteins and amino acids (Millon's test, Biuret test, Ninhydrin test, Legal's test, Keller-Killiani test), phytosterols (Liebermann- Burchard's test), fixed oils (Spot test, Saponification test), fats and gums and mucilages were performed. ${ }^{9,10}$

\section{Estimation of total phenolic content}

The total phenolic content of C. colebrookianum extract was estimated by the method adopted by Ordonez et al. ${ }^{11}$ using Folin-Ciocaltau reagent with slight alterations. The phenolics content of extracts was expressed in Gal- 
lic Acid Equivalents (GAE). All samples were analyzed in triplicates.

\section{Estimation of total flavonoids content (aluminum chloride colorimetric assay)}

The C. colebrookianum extract was diluted to a concentration of $1 \mathrm{mg} / \mathrm{mL}$ with ethanol and was further diluted. The diluted extract solution $(1 \mathrm{~mL})$ and $1 \mathrm{~mL}$ of $2 \% \mathrm{AlCl}_{3}$ solution was taken in a test tube and incubated at room temperature for an hour. The absorbance was analyzed using spectrophotometer (UV-1800 Shimadzu, Japan) at $415 \mathrm{~nm}$. The calibration curve of quercetin (standard compound) was prepared with concentrations between $10-90 \mu \mathrm{g} / \mathrm{mL}$. The flavonoids content of extracts was expressed in terms of Quercetin Equivalent (QE). ${ }^{12}$ All samples were analyzed in triplicates.

\section{Determination of Antioxidant activity (DPPH radical scavenging activity) of $C$. colebrookianum extract}

Radical scavenging activity of $C$. colebrookianum extracts against stable DPPH (1, 1-diphenyl-2-picrylhydrazyl hydrate) was determined spectrophotometrically. DPPH gets reduced when reacts with an antioxidant compound resulting change in color from deep-violet to light-yellow and was measured at $415 \mathrm{~nm}$ on a UV/ visible light spectrophotometer (UV-1800 Shimadzu, Japan). The free radical scavenging activity was measured by DPPH (1, 1-diphenyl-2-picryl-hydrazyl) employing the method described by Blois. ${ }^{13} 1 \mathrm{~mL}$ of $0.1 \mathrm{mM}$ solution of DPPH in ethanol was added to $3 \mathrm{~mL}$ of different concentrations $(5-100 \mu \mathrm{g} / \mathrm{mL})$ of the extract and incubated for 30 mins. The percentage of inhibition was calculated by comparing the absorbance of control with absorbance of test samples. Ascorbic acid was used as a reference compound. All the tests were performed in triplicate.

$$
\% \text { inhibition }=\frac{(\text { Absorbance of sample })}{(\text { Absorbance of control })} \times 100
$$

\section{Preparation of microballoons}

With slight modification, preparation of microballoons as reported by Kawashima et al. ${ }^{14}$ using emulsion solvent diffusion method. Ethyl cellulose was used as a polymer either alone or in mixture with other polymers such as HPMC, Eudragit S-100, Methylcellulose or PVP $\mathrm{K}-30$. At room temperature, $20 \mathrm{~mL}$ solution containing ethanol and dichloromethane (1:1) was taken for dissolving the polymers and extract. A solution containing $0.75 \% \mathrm{w} / \mathrm{v}$ polyvinyl alcohol and $0.2 \% \mathrm{w} / \mathrm{v}$ Tween 80 was prepared at $40^{\circ} \mathrm{C}$. Under continuous stirring (mechanical stirrer), the organic solvent was added drop wise to the aqueous solution at a phase volume ratio of 1:5. Three different levels of stirring speed i.e., at 200, 500 and $700 \mathrm{rpm}$ was taken to stir the resultant emulsion continuously. For a better diffusion of solvent in the aqueous phase, the optimum speed selected was $500 \mathrm{rpm}$. Ultimately leading to the evaporation of organic solvent under stirring. The microballoons formed were collected, washed with distilled water, dried in hot air oven and stored in vacuum desiccators. ${ }^{15-17}$ Details reported in Table 1.

\section{Evaluation of microballoons}

\section{Percentage Yield of microspheres}

Percentage (\%) yield was calculated by considering the total non-volatile ingredients used for the preparation of microballoons with the total weight of formed microballoons. ${ }^{18}$ The $\%$ yield was calculated using the following equation:

$$
\begin{aligned}
\% \text { yield }= & \frac{\text { (Weight of microballoons collected })}{\text { (Weight of extract }+ \text { polymer used for }} \times 100 \\
& \text { the preparation of microballoons) }
\end{aligned}
$$

\section{Determination of flow properties of microballoons}

Bulk density and tapped density were carried out using

\begin{tabular}{|c|c|c|c|c|c|c|c|}
\hline Formulation Code & Extract & $E C^{*}$ & HPMC\# & $P V P^{* *}$ & E\#\# & $M C^{* * *}$ & $\mathrm{EtOH}: \mathrm{CH}_{3} \mathrm{Cl}_{2}{ }^{\wedge \wedge}$ \\
\hline MC1 & $100 \mathrm{mg}$ & $2.3 \mathrm{~g}$ & - & - & - & - & $1: 1$ \\
\hline MC2 & $100 \mathrm{mg}$ & $2 \mathrm{~g}$ & $0.3 \mathrm{~g}$ & - & - & - & $1: 1$ \\
\hline MC3 & $100 \mathrm{mg}$ & $2 \mathrm{~g}$ & - & $0.3 \mathrm{~g}$ & - & - & $1: 1$ \\
\hline MC4 & $100 \mathrm{mg}$ & $2 \mathrm{~g}$ & - & - & $0.3 \mathrm{~g}$ & - & $1: 1$ \\
\hline MC5 & $100 \mathrm{mg}$ & $2 \mathrm{~g}$ & - & - & - & $0.3 \mathrm{~g}$ & $1: 1$ \\
\hline
\end{tabular}
Tap density tester (LABINDIA TD1025, INDIA) for the prepared formulation. In a graduated measuring cylinder $(10 \mathrm{~mL}), 1 \mathrm{~g}$ of formulation was weigh, trans-

*EC- Ethyl cellulose, "HPMC- Hydroxypropyl methylcellulose, ${ }^{* * P V P}$ - Polyvinylpyrrolidone K-30, ${ }^{* \# E-E u d r a g i t ~ S-100, ~}$ ${ }^{* * *} \mathrm{MC}$ - Methylcellulose, ${ }^{\wedge} \mathrm{EtOH}: \mathrm{CH}_{3} \mathrm{Cl}_{2}$ - Ethanol: dichloromethane 
ferred and the volume was noted. ${ }^{18}$ Followed by the determination of Carr's index and Hausner's ratio. ${ }^{19}$

The angle of repose was studied using fixed funnel method. Microballoons were poured through a funnel onto a graph paper where the tip was fixed at a minimum height of $2 \mathrm{~cm}$ above the cone. The angle of repose is the $\tan ^{-1}$ ratio of the height of the cone and radius of its base. ${ }^{18}$

\section{Determination of buoyancy}

Microballoons (50 mg) were transferred to a $100 \mathrm{~mL}$ Simulated Gastric Fluid (SGF), pH 1.2 comprising $0.02 \%$ Tween 20 (to prevent aggregation of microballoons) at $37^{\circ} \mathrm{C}$. At $100 \mathrm{rpm}$ the mixture was stirred using a magnetic stirrer. After $8 \mathrm{~h}$, the microballoons (floated and settled) were collected and separated, dried at $40^{\circ} \mathrm{C}$ and weighed. The buoyancy was calculated by the equation given below: ${ }^{20}$

$$
\begin{aligned}
\text { Buoyancy }(\%)= & \frac{(\text { Weight of floating microballoons })}{\text { (Weight of floating microballoons }+} \times 100 \\
& \text { Weight of settled microballoons) }
\end{aligned}
$$

\section{Determination of entrapment efficiency and drug loading}

C. colebrookianum extract was diluted to different concentration $20,40,60,80,100$ and $120 \mu \mathrm{g} / \mathrm{ml}$ for the standard calibration curve of flavonoids present in extract. $1 \mathrm{ml}$ of $\mathrm{AlCl}_{3}$ solution $(2 \%)$ was added to the diluted solution $(1 \mathrm{~mL})$, incubated for an hour at room temperature. The absorbance was measured using UV-spectrophotometer (UV1800, Shimadzu) at $415 \mathrm{~nm}$. Microballoons (10mg) were crushed, added to ethanol to dissolve the main components and filtered. The filtrate was taken for measurement to determine the absorbance by a UV-spectrophotometer (UV1800, Shimadzu) at wave length of $415 \mathrm{~nm} \cdot{ }^{21}$ Entrapment efficiency and drug loading was calculated using following formulae:

$$
\text { Entrapment efficiency }(\%)=\frac{\left(\begin{array}{l}
\text { Practical drug } \\
\text { content })
\end{array}\right.}{\begin{array}{c}
\text { Theoretical drug } \\
\text { content })
\end{array}} \times 100
$$$$
\text { Drug loading }=\frac{(\text { Amount of drug recorded })}{(\text { Amount of formulation taken })} \times 100
$$

\section{Scanning electron microscopy (SEM)}

External morphology of the prepared microballoons was analyzed by SEM both before and after release study. Using a double adhesive tape, the microballoons were mounted onto the aluminium stub. Using Jeol JFC 1100 sputter coater the stub was then coated with gold. The microballoons were observed at $15 \mathrm{kV}$ accelerating voltage. ${ }^{16}$ The analysis was performed by using Jeol JSM 6360, Japan.

\section{Infra-red Spectroscopy}

An IR Spectrum reveals the distinguishing peaks of the sample functional groups. For ascertaining any possible chemical interaction of extract, polymer, their physical mixture and extract loaded microballoons were exposed to FTIR studies. IR spectra were recorded using IR spectrophotometer (Shimadzu model 8400), between $500 \mathrm{~cm}^{-1}$ to $4000 \mathrm{~cm}^{-1}$ wavenumbers. ${ }^{16}$

\section{In vitro drug release and release kinetics studies}

The release profile from different formulation was determined using USP type II apparatus. Dissolution medium (SGF, pH 1.2, $900 \mathrm{~mL}$ ) containing $0.02 \%$ Tween 20 was filled in the dissolution vessel, temperature maintained at $37 \pm 0.5^{\circ} \mathrm{C}$ and stirred at $100 \mathrm{rpm}$. A weight amount of microballoons equivalent to $50 \mathrm{mg}$ of flavonoid was transferred to the dissolution vessel containing the dissolution medium. At a predetermined time intervals, aliquots were withdrawn till the $8^{\text {th }}$ hour. Samples were then analyzed by UV spectrophotometer (UV 1800, Shimadzu) at $415 \mathrm{~nm} \cdot{ }^{22}$ Data obtained after the in vitro drug release were statistically fitted to several kinetic models to determine the drug release kinetics for the microballoons.

\section{Antihypertensive activity}

In vivo Antihypertensive activity of $C$. colebrookianum extracts as well as the microballoons formed were carried out using of male wistar albino rats (Rattus albus), weighing 150-300g. The in vivo pharmacodynamic study was approved and certified (vide approval No. IAEC/DU/117, Dated 18/02/2016) by the Institutional Animal and Ethics Committee, Department of Pharmaceutical Sciences, Dibrugarh University (Reg No. 1576/GO/E Re/S/11/CPCSEA, Dated 23/12/2014), Dibrugarh, Assam, India.

\section{Induction of Two kidney one clip (2K1C) renal hypertension}

The rats were acclimatized for 7 days post which they were anesthetized with Ketamine $\mathrm{HCl}, 40 \mathrm{mg} / \mathrm{kg}$ (intraperitoneal injection). The experimental procedure was conducted under aseptic conditions. The animal left posterior side was shaved followed by sterilization with $70 \%$ ethanol. An incision was performed on the left flank to give entry to the left renal artery followed by isolation from the renal vein and connective tissue. The 
exposed renal artery was applied with silver clip with diameter (internal) of $0.2 \mathrm{~mm}$, which was turned with the goal that the opening slit facing the abdomen, bringing about fractional occlusion of the renal perfusion. The opposite kidney was not disturbed. After surgery, sutured the muscles and skin immediately, the rats were then allowed to recuperate from anesthesia. A sham treatment for the control group was achieved by undergoing the same procedure as $2 \mathrm{~K} 1 \mathrm{C}$ rats, except for the application of a clip. Animals were allowed to access $8 \% \mathrm{NaCl}$ solution. ${ }^{23,24}$ Blood pressure were measured by non-invasive tail cuff plethysmography method (Biopac system NIBP 200A, MP 36) and were considered hypertensive when the systolic pressure was over $160 \mathrm{mmHg}$. The rats of different groups were treated with oral administration of Propanolol (Standard drug), extract of C. colebrookianum with a dose of $100 \mathrm{mg} / \mathrm{kg}$ b.w. (CC100) and $200 \mathrm{mg} / \mathrm{kg}$ b.w. (CC200) and the formulation with a dose equivalent to $10 \mathrm{mg} / \mathrm{kg}$ flavonoid. ${ }^{25,26}$ The blood pressure was monitored over a period of 7 days and reported.

\section{Statistical Analysis}

The data presented here is for triplicate determinations $(n=3)$ and it is expressed as mean \pm SD. Antihypertensive activity data were investigated by One-way ANOVA, using Graph pad INSTAT. The post-hock analysis was performed by Dunnet's multiple comparison tests to evaluate the significance difference between individual groups $(* * P<0.01)$. Confidence interval has been considered as $99 \%$ and $p<0.01$ were considered significant. $\mathrm{IC}_{50}$ value was calculated by plotting a graph with percent inhibition on $y$-axis and concentration on $\mathrm{x}$-axis.

\section{RESULTS AND DISCUSSION}

\section{Phytochemical evaluation of plant extracts}

Phytochemical test revealed the constituents present which are well known for their vivid medicinal and physiological activities. The phytochemical evaluation of the ethanolic extracts were performed and the results were reported in Table 2 .

\section{Estimation of Total phenolic content}

The total phenolic content for C. colebrookianum extract using the Folin-Ciocalteu's reagent was found to be $621.32 \mathrm{mg}$ of $\mathrm{GAE} / \mathrm{g}$.

\section{Estimation of Total Flavonoid Content}

The flavonoid content for C. colebrookianum extract was found to be $539.7 \mathrm{mg}$ of Quercetin equivalent/g. In
Table 2: Phytochemical screening of ethanolic extract of C. colebrookianum.

\begin{tabular}{|c|c|}
\hline Test & Result \\
\hline Detection of Alkaloids & Positive \\
\hline Detection of Carbohydrates & Positive \\
\hline Detection of Saponins & Positive \\
\hline Detection of Phenolic Compounds & Positive \\
\hline Detection of Glycoside & Positive \\
\hline Detection of flavonoids & Positive \\
\hline Detection of Proteins and Amino Acids & Negative \\
\hline Detection of Phytosterols & Positive \\
\hline Detection of Fixed Oils and Fats & Negative \\
\hline Detection of Gums and Mucilage & Negative \\
\hline
\end{tabular}

brief, the flavonoid present in the extract reacts with the aluminium ion $\left(\mathrm{Al}^{3+}\right)$ to form the stable flavonoid- $\mathrm{Al}^{3+}$ complex, which has a yellow color and whose intensity is related to the concentration of flavonoid present in it. Flavonoids which are supposed to be the key components for demonstration of anti-hypertensive activity was confirmed by the test ${ }^{27,28}$ although other classes of compounds also may contribute for the blood pressure normalization to demonstrate a synergistic effect. Therefore it is expected that the extract would show a considerable reduction in blood pressure when formulated in a sustained release dosage form.

\section{Antioxidant Activity: DPPH radical scavenging activity of $C$. colebrookianum extract}

In DPPH free radical scavenging activity was performed and observed that there is an increased in scavenging effect with increase concentration of $C$. colebrookianum extract. It was also observed that at same concentration ascorbic acid expressed the highest \% inhibition i.e. $94.56 \%$ than C. colebrookianum extract with $73.75 \%$, with $\mathrm{IC}_{50}$ of $123.21 \mu \mathrm{g} / \mathrm{mL}$ for standard, whereas for extract it was $133.44 \mu \mathrm{g} / \mathrm{mL}$. Hence, C. colebrookianum can be used as good source of antioxidant which may be an important factor to efficiently lower the blood pressure, by decreasing the aldehyde conjugate/AGE formation resulting in reduced oxidative stress and enhancing insulin resistance and other endothelial functions. ${ }^{3,29-31}$

\section{Preparation of Microballoons}

The microballoons containing C. colebrookianum extract were prepared by emulsion solvent diffusion method using ethyl cellulose as polymer either alone or on mixture with other polymers (composition details were reported in Table 1) to manipulate the formulation yield, encapsulation/loading efficiency and release 
kinetics of bioactive extract in the formulation. The central hollow core of microballoons is most likely due to the difference in diffusion rate and miscibility of ethanol and dichloromethane in aqueous phase. In the primary stage of microballoons formation, ethanol diffuses readily from the aqueous phase due to its high miscibility followed by the slow diffusion of dichloromethane leading to the development of the central hollow space filled with water. This water was evaporated from the cavity through the porous surface while drying at controlled temperature, eventually forming hollow microballoons. ${ }^{32}$ The development of microballoons had been confirmed in further evaluation studies.

\section{Evaluation of Microballoons}

The Percentage yield, Bulk density, Tapped density, Carr's index, Haursner Ratio and Angle of repose of all formulations were reported in the Table 3. MC1 have the lowest yield with MC3 showing the highest product yield which may attribute to the binding capacity of PVP. The lower the value of Carr's index better will be the flow properties, values higher than 25 is said to give a poor flowability. ${ }^{33}$ The results show that $\mathrm{MC1}$ and MC4 exhibit a good flow and the others i.e. MC2, MC3 and MC5 have a fair flow property. Hausner's ratio of 1.25 or less is said to give good flow ability of materials. ${ }^{34}$ The MC2 showed a poor flow properties while all the others give a good flow properties. In the present study, the angle of repose varies from $20.02^{\circ} \mathrm{C}-33.36^{\circ} \mathrm{C}$ depending on nature of formulation. Overall after characterizing the flow property, the angle of repose values of all micro balloons were acceptable as free-flowing as they did not exceed $35^{\circ} \mathrm{C}$.

\section{Floating / Buoyancy Test}

All microspheres showed a floating ability or buoyancy varying between $70.18 \%-89.90 \%$ up to $8 \mathrm{hr}$ (Table 3). The buoyancy is credited to the air core hollow structure of microballoons formed after the evaporation of solvent. Floatation studies indicate that all the formulation had good buoyancy. MC3 showed the highest \% buoyancy.

\section{Entrapment efficiency and Drug Loading}

The formulations were calculated for drug entrapment efficiency and loading using equation 4 and 5 respectively. From Table 3, revealed that MC3 showed entrapment efficiency better than the other, which may thus be inferred that ethyl cellulose along with PVP to formed a uniform and effective outer layer. Drug loading remained almost similar in all the five formulations.

\section{Compatibility study: FTIR Spectroscopy}

From Figure 1, FTIR of C. colebrookianum extract, ethyl cellulose, PVP K-30, physical mixture and MC3 formulation revealed a similar characteristic peaks. Thus it can be concluded that there is no possible chemical interaction between the extract and the excipients and it indicates the integrity and compatibility of the polymer and the extract.

\section{Scanning Electron Microscopy study}

SEM images of microballoons provide information about particle shape, size and external morphology of the formulations. Microballoons were observed to be spherical and porous in nature with central hollow core as showed in Figure 2, which were accountable for the floating behaviour. The pores on the surface were observed to increase in diameter after dissolution study confirming the theory of diffusion from insoluble matrix to be the mechanism of drug release.

\section{In vitro Drug release study and Release order kinetics study}

The in-vitro drug release studies from all the formulations revealed an early burst release of flavonoid from microballoons, followed by gradual retarded release of

\begin{tabular}{|c|c|c|c|c|c|}
\hline \multicolumn{7}{|c|}{ Table 3: Physicochemical and in vitro evaluation of microballoons. } \\
\hline Formulation & MC1 & MC2 & MC3 & MC4 & MC5 \\
\hline Percentage of Yield (\%) & $47.43 \pm 0.02$ & $58.30 \pm 0.2$ & $68.45 \pm 0.015$ & $63.15 \pm 0.005$ & $58.99 \pm 0.118$ \\
\hline Bulk density (gm/cm3) & $0.072 \pm 0.001$ & $0.088 \pm 0.001$ & $0.13 \pm 0.005$ & $0.072 \pm 0.001$ & $0.13 \pm 0.005$ \\
\hline Tapped density (gm/cm3) & $0.081 \pm 0.001$ & $0.113 \pm 0.001$ & $0.16 \pm 0.005$ & $0.082 \pm 0.005$ & $0.158 \pm 0.001$ \\
\hline Carr's Index (\%) & $11.11 \pm 0.010$ & $22.22 \pm 0.010$ & $20 \pm 0.550$ & $12.27 \pm 0.010$ & $17.98 \pm 0.020$ \\
\hline Hausner's ratio & $1.125 \pm 0.001$ & $1.28 \pm 0.010$ & $1.25 \pm 0.005$ & $1.139 \pm 0.001$ & $1.219 \pm 0.001$ \\
\hline Angle of repose ( $\theta)$ & $29.57 \pm 0.005$ & $30.26 \pm 0.010$ & $29.83 \pm 0.010$ & $32.62 \pm 0.005$ & $27.79 \pm 0.005$ \\
\hline Buoyancy Test (\%) & $78.26 \pm 0.025$ & $77.94 \pm 0.020$ & $89.90 \pm 0.064$ & $75.55 \pm 0.052$ & $80.69 \pm 0.032$ \\
\hline Entrapment Efficiency (\%) & $52.09 \pm 0.005$ & $63.40 \pm 0.100$ & $81.3 \pm 0.100$ & $68.28 \pm 0.010$ & $69.31 \pm 0.020$ \\
\hline Drug Loading (\%) & $3.38 \pm 0.005$ & $3.35 \pm 0.01$ & $3.65 \pm 0.01$ & $3.33 \pm 0.025$ & $3.62 \pm 0.037$ \\
\hline
\end{tabular}

Values are expressed as Mean $\pm S D$; where $n=3$. 


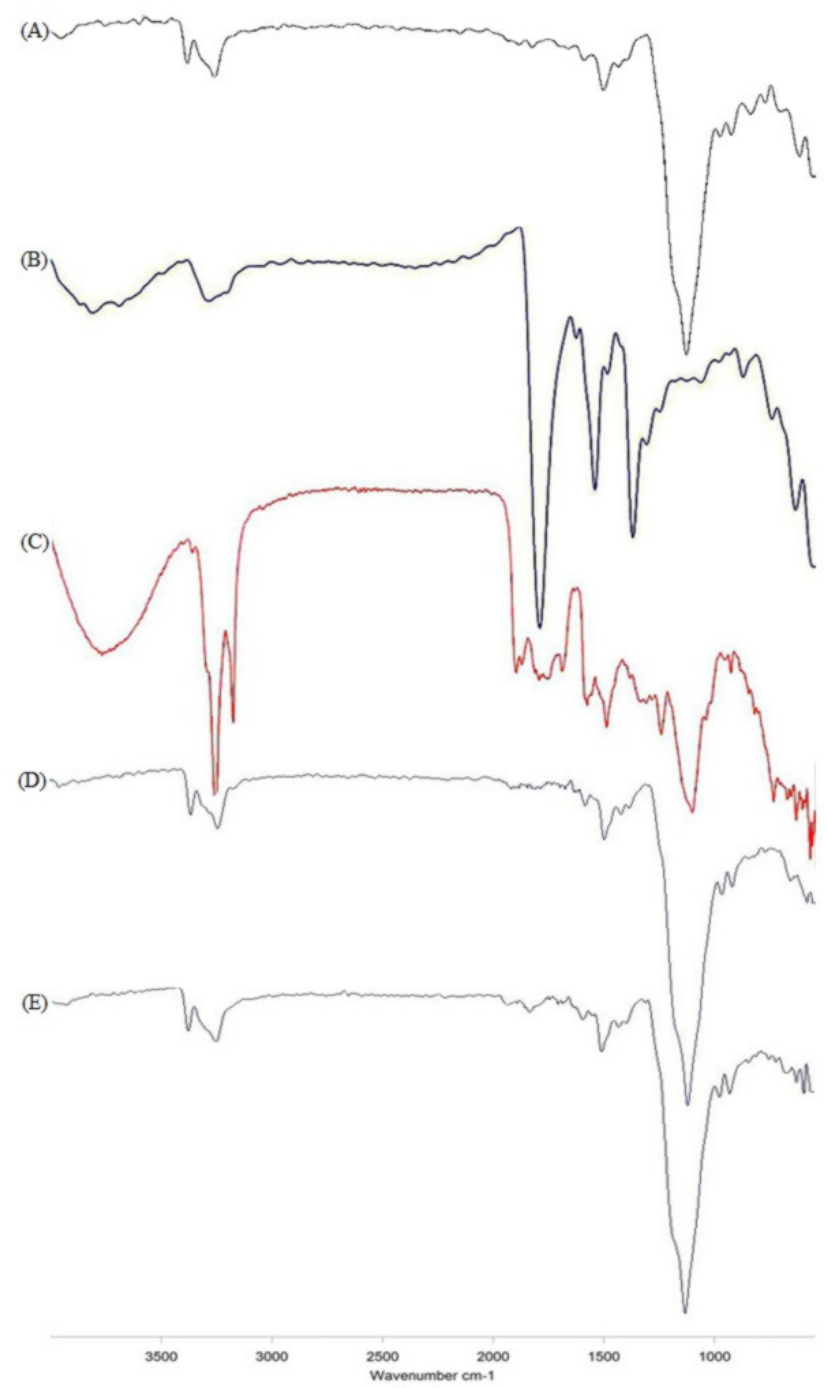

Figure 1: Compatibility study by FTIR spectrum: (A) Ethylcellulose (B) PVP K-30 (C) C. colebrookianum extract (D) physical mixture of Ethylcellulose + PVP K-30 + C. colebrookianum extract (E) MC3 formulation.

flavonoid in stimulated gastric fluid, ranging between 1.15-28.09\%, with MC3 formulation gives better release of flavonoid $(28.09 \%$ for $8 \mathrm{hr})$ compared to others as shown in Figure 3. MC3 in-vitro release studies data were fitted to several release kinetics models to understand it's drug release mechanism. The highest regression was obtained for Higuchi (0.981) followed by first order (0.9641), zero order (0.9536) then Hixon Crowell (0.6694). To determine the release kinetics of the prepared formulations, the dissolution data was analyzed using korsmeyer-Peppas equation. Here, after the values of percentage of cumulative drug release are fitted to the equation and it was observed that MC3 formulation followed super case-II transport. From the release kinetic study, release of flavonoid from the microballoon MC3 was observed to follows Higuchi Model which

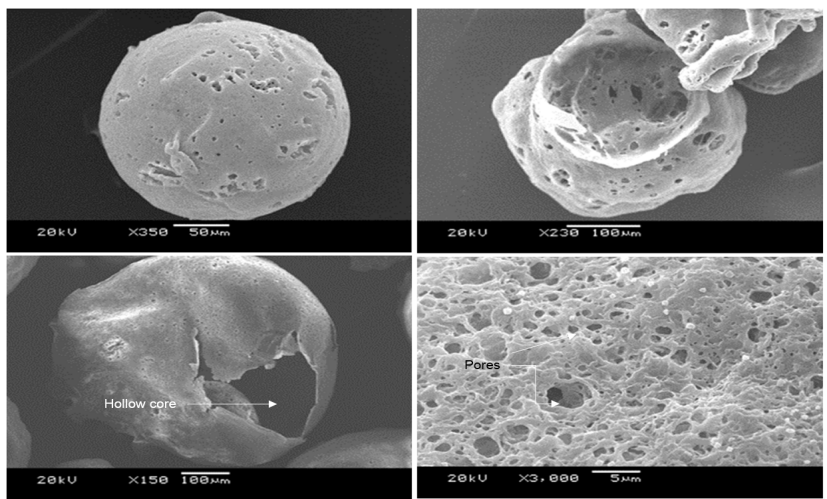

Figure 2: Scanning Electron Microscopy (SEM) images of microballoons displaying their spherical shape, centre hollow and porous nature.

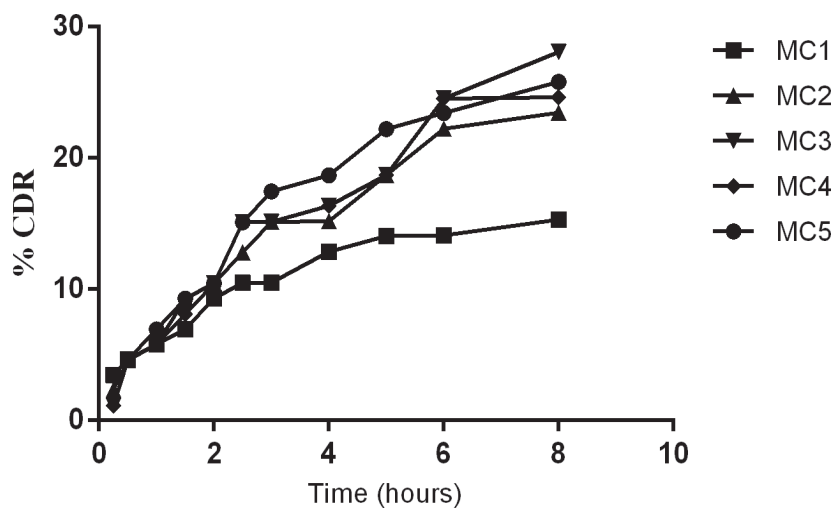

Figure 3: In vitro release of flavonoids from experimental microballoons.

describes that the uniform dispersion of drug in matrix media and drug release rate is associated to the drug diffusion rate.

\section{Antihypertensive activity of $C$. colebrookianum extract and Microballoons}

The activity of $C$. colebrookianum extracts as well as prepared extract loaded microballoons was checked using in vivo animal model. From Table 4 and Figure 4, it can be said that C. colebrookianum extract showed activity at both levels of dosing $(100 \mathrm{mg} / \mathrm{kg}$ b.w. and $200 \mathrm{mg} / \mathrm{kg}$ b.w.), where the high dose gives a better activity than the low dose. The oral administration of formulation MC3 demonstrated better antihypertensive activity after dosing than the crude extract. This may be because of increased gastric retention of extract when it was formulated as floating microballoons, resulting in enhancement of bioavailability of active molecule although one tenth of the extract dose was administered. The efficacy to reduce the arterial blood pressure by the C. colebrookianum extract and propanolol confirms the potency of extract to be safe in treatment of hypertension. This fact may be credited to the presence 


\begin{tabular}{|c|c|c|c|c|c|c|}
\hline Particulars & $\begin{array}{l}\text { Positive } \\
\text { control }\end{array}$ & Negative control & Standard & CC 100 & CC 200 & MC3 \\
\hline $\begin{array}{c}\text { Before treatment } \\
\text { (Compared with control) }\end{array}$ & $99.66 \pm 2.074$ & $94.40 \pm 4.35$ & $91.39 \pm 1.57^{* *}$ & $97.30 \pm 2.759$ & $93.39 \pm 7.24^{*}$ & $94.38 \pm 1.91$ * \\
\hline $\begin{array}{c}\text { Before treatment } \\
\text { (Compared with standard) }\end{array}$ & $99.66 \pm 2.0^{\star *}$ & $94.40 \pm 4.3$ & $91.39 \pm 1.5$ & $97.30 \pm 2.7^{*}$ & $93.39 \pm 7.2$ & $94.38 \pm 1.9$ \\
\hline $\begin{array}{c}\text { After treatment } \\
\text { (Compared with Control) }\end{array}$ & $99.52 \pm 1.1$ & $139.61 \pm 11.7^{* *}$ & $88.11 \pm 1.9^{* *}$ & $94.54 \pm 2.13$ & $91.79 \pm 5.8$ * & $92.16 \pm 1.6^{*}$ \\
\hline $\begin{array}{c}\text { After treatment } \\
\text { (Compared with standard) }\end{array}$ & $99.52 \pm 1.17^{\star *}$ & $139.61 \pm 11.71^{* *}$ & $88.11 \pm 1.93$ & $94.54 \pm 2.13$ & $91.79 \pm 5.8$ & $92.16 \pm 1.66$ \\
\hline
\end{tabular}

Values are expressed as Mean \pm SD., where $n=6$. One Way ANOVA followed by Turkey-Kramer Multiple Comparison test *Less significant; **Moderately significant where $p<0.01 \mathrm{vs}$. control group / standard group

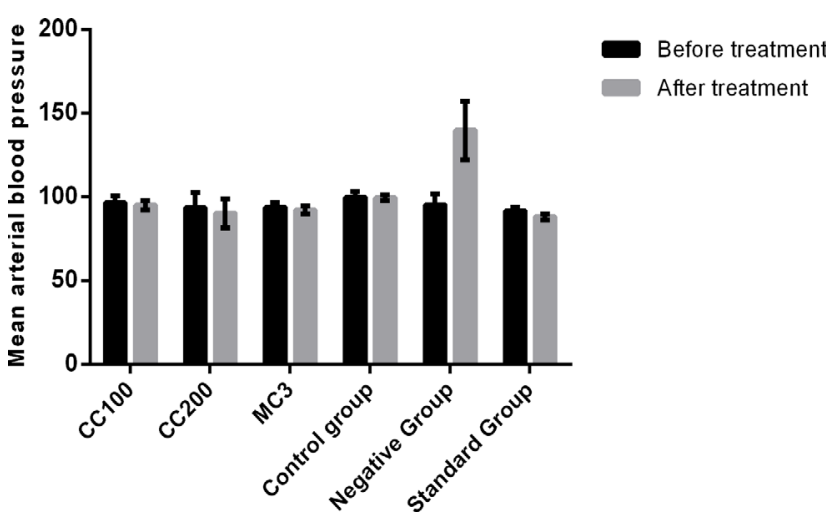

Figure 4: In vivo antihypertensive study in rat model.

of antioxidants like flavonoid present in the extract. Reduction in blood pressure in standard group and both the test groups was found significant when compared with negative control group.

\section{CONCLUSION}

In summary, successful development of extended release antihypertensive microballoons containing C. colebrokianum extract were effectively prepared and evaluated. It was additional confirmed from the in vivo studies, that extract loaded MC3 microballoons were effective in the management of hypertension. In future, with intense and insightful study, C. colebrokianum extract can be processed to isolate to pure bioactive compound responsible for producing the anti-hypertensive activity. The potent bioactive molecule can then be further formulated as novel formulations for example microballoons or any other sustained release system for safe and effective management of hypertension.

\section{ACKNOWLEDGEMENT}

The authors are thankful to SAIF, NEHU, Shillong, Meghalaya, India for providing SEM imaging facilities that has been reproduced in the paper. The authors also extend their gratitude towards Division of Pharmaceutical Technology, Defence Research Laboratory, Tezpur, Assam, India to share their expertise. The authors are grateful to Dibrugarh University for providing a Central Animal House Facility and funding the research work. The authors acknowledge the electronic journal consortium DeLCON, DBT

\section{CONFLICT OF INTEREST}

The authors declare no conflicts of interest.

\section{ABBREVIATIONS}

ROS: Reactive oxygen species; DASH: Dietary Approaches to Stop Hypertension; GRT: Gastric Residence Time; CMC: Carboxy methylcellulose, GAE: Gallic acid equivalents; QE: Quercetin equivalent; DPPH: 1, 1-diphenyl-2-picrylhydrazyl hydrate; SGF: Simulated gastric fluid; SEM: Scanning electron microscopy; FT-IR: Fourier Transforms-Infra Red; 2K1C: Two kidney one clip.

\section{REFERENCES}

1. World Health Organization. Cardiovascular diseases. 2017. http://www.who. int/cardiovascular diseases/en/

2. World Health Organization. A global brief on hypertension - silent killer, public health crisis. 2017. http://www.who.int/cardiovascular_diseases/publications/ global_brief hypertension/en/

3. Vasdev S, Gill V. Antioxidants in the Treatment of Hypertension. Int J Angiol. 2005;14(2):60-73.

4. Deb L, Dutta A. Evaluation of mechanism for antihypertensive action of Clerodendrum colebrookianum used by folklore healers in North East India. J Ethnopharmacol. 2012;143(1):207-12.

5. Kotoky J, Dasgupta B, Deka N. Pharmacological studies of Clerodendron colebrookianum Walp, a potent hypotensive plant. Indian J Physiol Pharmacol. 2005;49(3):289-96.

6. Kalita J, Singh SS, Khan ML. Clerodendrum colebrookianum Walp. A potential folk medicinal plant of North East India. Asian J Pharm Biol Res. 2012;2(4):256-61. 
7. Gupta P, Preeti K. Floating Drug Delivery System: A Review. Int J Pharm Res Rev. 2015;4(8):37-44.

8. Sato $\mathrm{Y}, \mathrm{Kawashima} \mathrm{Y}$, Takeuchi $\mathrm{H}$, et al. In vitro evaluation of floating and drug releasing behaviors of hollow microspheres (microballoons) prepared by the emulsion solvent diffusion method. Eur J Pharm Biopharm. 2004;57(2):235-43.

9. Kokate CK. Practical Pharmacognosy. $4^{\text {th }}$ ed. New Delhi: Vallabh Prakashan. 2005.

10. Harborne JB. Phytochemical methods, A Guide To modern Technique of Plant Analysis. $3^{\text {rd }}$ ed. London, UK: Chapman and Hall. 1998.

11. Ordonez AAL, Gomez JD, Vattuone MA, et al. Antioxidant activities of Sechium edule (Jacq.) Swartz extracts. Food Chemistry. 2006;97(3):452-8.

12. Jain PK, Agrawal RK. Antioxidant and free radical scavenging properties of developed mono-and polyherbal formulations. Asian J Exp Sci. 2008;22(3):213-20.

13. Blois MS. Antioxidant determinations by the use of a stable free radical. Nature. 1958;181:1199-200.

14. Kawashima Y, Niwa T, TakeuchiH, et al. Preparation of multiple unit hollow microspheres (microballoons) with acrylic resin containing tranilast and their drug release characteristics (in vitro) and floating behavior (in vivo). J Control Release. 1991;16(3):279-90.

15. Kawashima $\mathrm{Y}$, Niwa $\mathrm{T}$, Takeuchi $\mathrm{H}$, et al. Hollow microspheres for use as a floating controlled drug delivery system in the stomach. J Pharm Sci. 1992;81(2):135-40.

16. Saravanan M, Anupama B. Development and evaluation of ethylcellulose floating microspheres loaded with ranitidine hydrochloride by novel solvent evaporation-matrix erosion method. Carbohydrate Polymers. 2011;85(3):592-8.

17. Choudhary S, Jain A, Amin MC, et al. Stomach specific polymeric low density microballoons as a vector for extended delivery of rabeprazole and amoxicillin for treatment of peptic ulcer. Colloids Surf B Biointerfaces. 2016;141:268-77.

18. Gupta. R, Prajapati SK, Pattnaik S, et al. Formulation and evaluation of novel stomach specific floating microspheres bearing famotidine for treatment of gastric ulcer and their radiographic study. Asian Pac J Trop Biomed. 2014;4(9):729-35.

19. Sanchan N, Bhattacharya A. A modelling and characterization of drug release from glutinous rice starch based hydrogel beads for control drug delivery. Int J Health Res. 2009;2(1):93-9.
20. Biswas N, Sahoo RK. Tapioca starch blended alginate mucoadhesive-floating beads for intragastric delivery of Metoprolol Tartrate. Int J Biol Macromol. 2016;83:61-70.

21. Awasthi R, Kulkarni GT. Development and characterization of amoxicillin loaded floating microballoons for the treatment of Helicobacter pylori induced gastric ulcer. Asian J Pharm Sci. 2013;8(3):174-80.

22. Sharma M, Kohli S, Dinda A. In-vitro and in-vivo evaluation of repaglinide loaded floating microspheres prepared from different viscosity grades of HPMC polymer. Saudi Pharm J. 2015;23(6):675-82.

23. Kaur M, Rana AC, Kumar S. Induction of hypertension by various animal models. Int J Pharm Biol Sci. 2011;1(3):335-40.

24. Badyal DK, Lata H, Dadhich AP. Animal models of hypertension and effect of drugs. Indian J Pharmacol. 2003;35(6):349-62.

25. Duarte J, Perez-Palencia R, Vargas F, et al. Antihypertensive effects of the flavonoid quercetin in spontaneously hypertensive rats. $\mathrm{Br} \mathrm{J}$ Pharmacol. 2001;133(1):117-24.

26. Morales-Cano D, Menendez C, Moreno E, et al. The Flavonoid Quercetin Reverses Pulmonary Hypertension in Rats. Plos One. 2014;9(12)1-20.

27. Hodgson JM, Croft KD. Dietary flavonoids: effects on endothelial function and blood pressure. J Sci Food Agri. 2006;86(15):2492-8.

28. Edwards RL, Lyon T, Litwin SE, et al. Quercetin Reduces Blood Pressure in Hypertensive Subjects. J Nutr. 2007;137(11):2405-11.

29. Montezano AC, Touyz RM. Molecular Mechanisms of Hypertension-Reactive Oxygen Species and Antioxidants: A Basic Science Update for the Clinician. Canadian Journal of Cardiology. 2012;28(3):288-95.

30. Kizhakekuttu TJ, Widlansky ME. Natural Antioxidants and Hypertension: Promise and Challenges. Cardiovasc Ther. 2010;28(4):e20-e32.

31. Ortiz MC, Manriquez MC, Romero JC, et al. Antioxidants Block Angiotensin II-Induced Increasesin Blood Pressure and Endothelin. Hypertension. 2001;38(2):655-9.

32. Mukund JY, Kanyilal BR, Sudhakar RN. Floating microspheres: A review. Braz J Pharm Sci. 2012;48(1):17-30.

33. Florence AT, Attwood D. Physicochemical Principles of Pharmacy: In Manufacture, Formulation and Clinical use, $6^{\text {th }}$ edition. London: Pharmaceutical Press. 2016;67.

34. Ma JKH, Hadzija B. Basic Physical Pharmacy. Burlington: Jones and Barlett Learning. 2012.

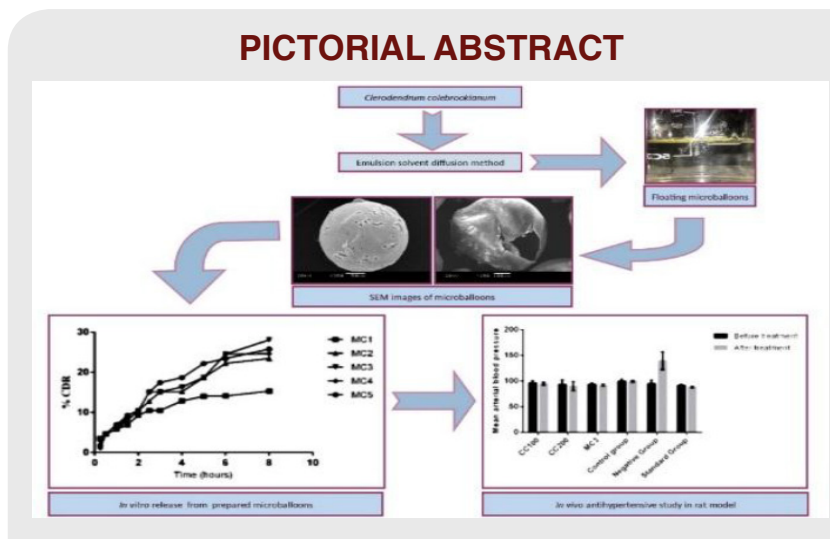

\section{SUMMARY}

In this study the crude extract from the leaf Clerodendrum colebrookianum Walp. a traditionally known antihypertensive plant which was formulated into microballoons a floating drug delivery system. The basic idea behind the development of such a system is to achieve a sustained release thus maintaining a constant level of drug in the blood plasma. The novelty of the work is combination of traditional system of medicine with novel drug delivery system.

Cite this article: Marbaniang D, Das RJ, Pal P, Saikia A, Pathak MP, Mandal S, et al. Extended Release Floating Microballoons Containing Clerodendrum colebrookianum Extract: In vitro in vivo Evaluation. Indian J of Pharmaceutical Education and Research. 2019;53(3 Suppl 2):s246-s254. 